\title{
Synthetic Cannabinoid Use Among High School Seniors
}

\author{
Joseph J. Palamar, PhD, MPH, ${ }^{a}$ Monica J. Barratt, BSc(Hons), PhD, b,c,d Leigh Coney, BSc, PGDip, ${ }^{\text {b }}$ Silvia S. Martins, MD, PhDe
}

OBJECTIVES: In this study, we examined the prevalence and correlates of current synthetic cannabinoid (SC) use among high school seniors in the United States.

METHODS: Monitoring the Future, an annual nationally representative survey of high school seniors, began querying current (30-day) SC use in 2014. Data were examined from the 2 most recent cohorts (2014-2015; $N=7805)$. Prevalence of self-reported use was examined and differences in demographics and recency and frequency of other drug use was compared between current marijuana-only users and current SC (plus marijuana) users using $\chi^{2}$ and generalized linear model using Poisson.

RESULTS: We found that $2.9 \%$ of students reported current SC use; $1.4 \%$ of students $(49.7 \%$ of users) reported using SCs on $\geq 3$ days in the past month. SC users were more likely to report more recent (and often more frequent) use of lysergic acid diethylamide, cocaine, heroin, and/or nonmedical use of opioids compared with marijuana-only users. Compared with current marijuana-only users, SC users were more likely to report lower parent education $(P<.05)$ and current use of a higher number of illegal drugs other than marijuana ( $P s<$ .001). Students using SCs $\geq 10$ times in the past month were more likely to be boys, frequent marijuana users $(P \mathrm{~s}<.01)$, African American, and users of multiple other illegal drugs ( $P \mathrm{~s}<$ $.001)$.

concLusions: SC use is typically part of a repertoire of polydrug use, and polydrug use is less prevalent among marijuana-only users. Current SC users are at risk for poisoning from use of the newest generation of SCs and from concurrent drug use.

${ }^{a}$ Department of Population Health, Langone Medical Center, New York University, New York, New York; ${ }^{b}$ Drug Policy Modelling Program, National Drug and Alcohol Research Centre, University of New South Wales, Sydney, Australia; ' National Drug Research Institute, Faculty of Health Sciences, Curtin University, Bentley, Australia; ${ }^{d}$ Behaviours and Health Risks Program, Burnet Institute, Melbourne, Australia; and ${ }^{e}$ Department of Epidemiology, Mailman School of Public Health, Columbia University, New York, New York

Dr Palamar conceptualized and designed the study, conducted the statistical analyses, helped draft the initial manuscript, critically reviewed the manuscript, and reviewed and revised the manuscript; Dr Barratt and Mr Coney helped draft the initial manuscript, helped interpret results, critically reviewed the manuscript, and reviewed and revised the manuscript; Dr Martins mentored Dr Palamar regarding statistical analysis, helped draft the initial manuscript, helped interpret results, critically reviewed the manuscript, and reviewed and revised the manuscript; and all authors approved the final manuscript as submitted.

DOI: https://doi.org/10.1542/peds.2017-1330

Accepted for publication Jul 11, 2017

Address correspondence to Joseph J. Palamar, PhD, MPH, Department of Population Health, New York University Langone Medical Center, 227 E. 30th St, 7th Floor, New York, NY 10016. E-mail: joseph.palamar@nyumc.org

PEDIATRICS (ISSN Numbers: Print, 0031-4005; Online, 1098-4275).

Copyright (C) 2017 by the American Academy of Pediatrics
WHAT'S KNOWN ON THIS SUBJECT: Synthetic cannabinoids are potent new psychoactive compounds that can result in adverse health outcomes, and marijuana users are at high risk for use. Researchers have examined use among high school students, but research is lacking regarding current (past 30-day) use.

WHAT THIS STUDY ADDS: This is the first nationally representative study in which current use of synthetic cannabinoids is examined. In this study, we found that $3 \%$ of high school seniors reported current use, and current users also tend to be current users of other drugs.
To cite: Palamar JJ, Barratt MJ, Coney L, et al. Synthetic Cannabinoid Use Among High School Seniors. Pediatrics. 2017;140(4):e20171330 


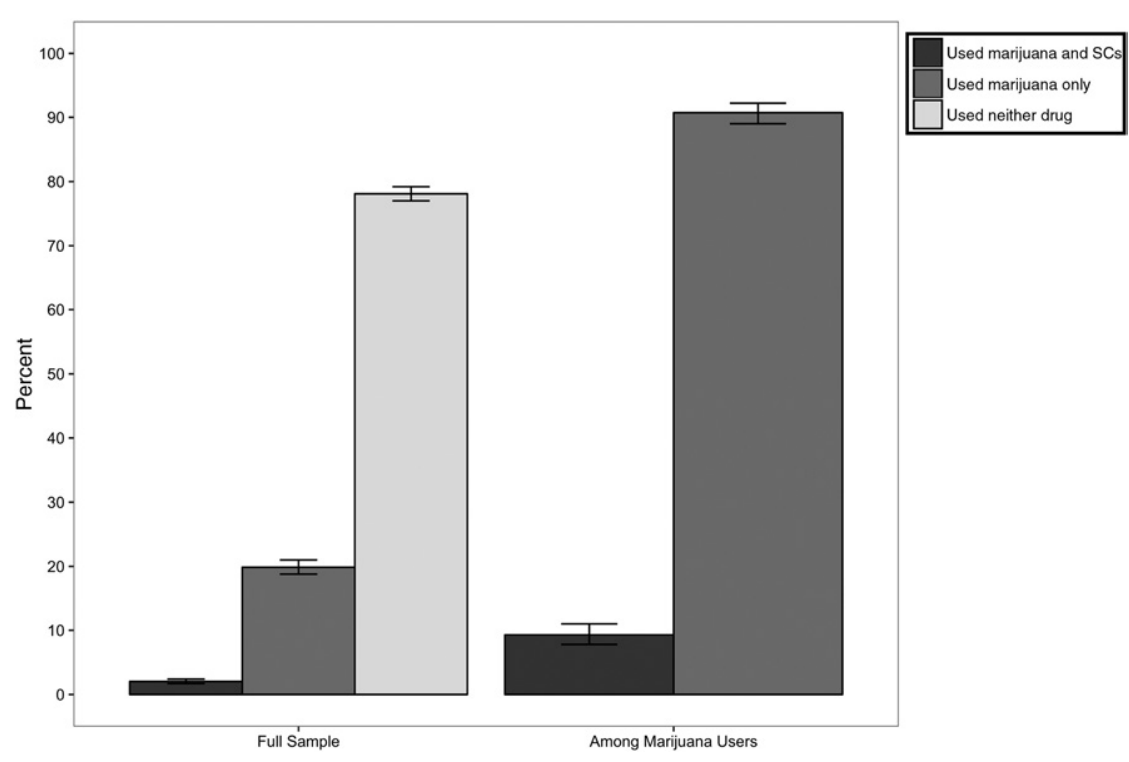

FIGURE 1

Percentages of current use of marijuana-only and SC and marijuana use among the full sample, and use of SC and marijuana among the marijuana-using subsample.

Synthetic cannabinoids (SCs), also known as $\mathrm{SC}$ receptor agonists, form a heterogeneous group of psychoactive substances that bind to one of the 2 known cannabinoid receptors. ${ }^{1}$ Although some of these compounds may resemble $\Delta^{9}$-tetrahydrocannabinol, the main psychoactive component in marijuana, SCs with completely different chemical structures have been identified. There are at least 14 chemically-diverse families of SCs, and they appear to be increasing in potency. ${ }^{2}$ The number of such compounds discovered has increased incrementally every year. ${ }^{3}$ Although these compounds are commonly marketed as being similar to marijuana (often under names such as Spice and K2), the potency is 2 to 100 times stronger than that of marijuana ${ }^{4}$ and does not contain the anxiolytic and antipsychotic component of marijuana, cannabidiol ${ }^{5}$; therefore, these compounds typically do not mimic effects of natural marijuana as widely thought. SCs are sprayed onto dried plant matter, and sold as "herbal incense," sold as "legal" marijuana labeled "not for human consumption," or alternatively are available as powders and sold as "research chemicals." 6

The high potency of SCs and overactivation of CB1 receptors are a likely cause of wide-ranging adverse effects commonly associated with use. ${ }^{7}$ A systematic review of 106 studies revealed 4000 cases of SC use in medical literature and poison center data. Common adverse effects included tachycardia (37\%-77\%), agitation $(16 \%-41 \%)$, nausea (13\%-94\%), generalized tonic-clonic seizures (4\%-15\%), 27 deaths, and psychiatric problems such as firstepisode psychosis. ${ }^{8}$ Additionally, SCs were analytically confirmed in cases of convulsions, ${ }^{9}$ seizures, ${ }^{10}$ acute kidney injury, ${ }^{11}$ acute cerebral ischemia, ${ }^{12}$ and myocardial infarction..$^{13}$ The rate of emergency medical treatment seeking after use has been estimated to be 30 times the rate of emergency medical treatment after marijuana use. ${ }^{14}$ In a study in which presentations during emergency department visits are compared, SC cases were found to have more "pronounced neurotoxicity and cardiotoxicity" compared with marijuana cases. ${ }^{15}$
SC use has been found to be strongly associated with marijuana use, ${ }^{16}$ with some studies revealing $\geq 95 \%$ of past-year SC users reporting lifetime marijuana use. ${ }^{16-18}$ Almost all past-year users have also been, or currently are, marijuana users, ${ }^{17-19}$ and a recent longitudinal study of adolescents revealed that marijuana use predicted SC use, but SC use did not predict marijuana use, suggesting marijuana use usually precedes SC use. ${ }^{20}$ In addition, frequency of marijuana use has been found to be one of the strongest correlates of SC use. ${ }^{16}$ However, 1 study revealed that $93 \%$ of users preferred marijuana over SCs, and users rated SCs more highly regarding negative effects. ${ }^{17}$ Although previous studies have revealed robust associations between lifetime use of other drugs and pastyear and lifetime use of SCs, ${ }^{16,21}$ more information is needed regarding how recency of use of other drugs relates to $\mathrm{SC}$ use to better inform prevention.

The prevalence of SC use has been found to be relatively high in young US populations. A study in which data were examined from Monitoring the Future (MTF), a nationally representative sample of high school students in the United States, revealed that from 2011 to $2013,10.1 \%$ of high school seniors reported past-year use of SCs, with $3 \%$ of high school seniors reporting more frequent use (used $\geq 6$ times). ${ }^{16}$ A steady decline in the prevalence of past-year use among high school seniors has been observed, with $11.4 \%$ reporting use in 2011 and $3.5 \%$ reporting use in $2016.22,23$ However, SCs still appear to be relatively attractive to some younger people; past-year use in 2016 was reported by $2.7 \%$ of eighth-graders, $3.3 \%$ of 10 th-graders, and $3.5 \%$ of 12 th-graders. ${ }^{22,24}$

Because of the potential harms associated with SC use, data on prevalence of use are necessary to understand which users are still at risk. To date, all national prevalence 
TABLE 1 Bivariable Tests Revealing Demographics and Recency of Use of Other Drugs According to Current SC and Marijuana Use

\begin{tabular}{|c|c|c|c|c|c|}
\hline & $\begin{array}{l}\text { Full Sample } \\
(N=7517), \\
\text { Weighted \% }\end{array}$ & $\begin{array}{l}\text { Used Neither } \\
\begin{array}{c}(n=5851 \\
78.1 \%) \\
\text { Weighted \% }\end{array}\end{array}$ & $\begin{array}{c}\text { Marijuana } \\
\text { Only }(n=1502, \\
19.9 \%), \\
\text { Weighted \% }\end{array}$ & $\begin{array}{c}\text { Marijuana } \\
\text { and SCs } \\
(n=164,2.0 \%), \\
\text { Weighted \% }\end{array}$ & $\begin{array}{c}P \text { (Marijuana } \\
\text { Only Versus } \\
\text { Marijuana } \\
\text { and SCs) }\end{array}$ \\
\hline Age & & & & & .45 \\
\hline$<18$ & 43.1 & 43.1 & 43.3 & 39.7 & \\
\hline$\geq 18$ & 56.9 & 56.9 & 56.7 & 60.3 & \\
\hline Sex & & & & & .44 \\
\hline Male & 46.5 & 45.0 & 51.7 & 55.5 & \\
\hline Female & 53.5 & 55.0 & 48.3 & 44.5 & \\
\hline Race and/or ethnicity & & & & & .06 \\
\hline White & 66.4 & 66.2 & 68.0 & 57.1 & \\
\hline African American & 14.8 & 15.0 & 13.7 & 15.9 & \\
\hline Hispanic & 18.9 & 18.8 & 18.3 & 26.9 & \\
\hline Parent education & & & & & .02 \\
\hline Low & 30.7 & 29.9 & 32.2 & 45.0 & \\
\hline Medium & 27.2 & 27.2 & 27.4 & 24.7 & \\
\hline High & 42.1 & 42.9 & 40.4 & 30.3 & \\
\hline \multicolumn{6}{|l|}{$\begin{array}{l}\text { Recency of other drug } \\
\text { use }\end{array}$} \\
\hline Alcohol & & & & & $.01^{\mathrm{a}, \mathrm{b}}$ \\
\hline Never used & 35.0 & 43.1 & 6.7 & 3.0 & \\
\hline $\begin{array}{l}\text { Lifetime, but not } \\
\text { past } 12 \mathrm{mo}\end{array}$ & 4.8 & 5.6 & 1.8 & 1.6 & \\
\hline $\begin{array}{l}12 \mathrm{mo} \text {, but not past } \\
30 \mathrm{~d}\end{array}$ & 23.5 & 24.4 & 21.1 & 10.6 & \\
\hline Past $30 \mathrm{~d}$ & 36.7 & 26.9 & 70.4 & 84.8 & \\
\hline LSD & & & & & $<.0001^{\mathrm{b}}$ \\
\hline Never used & 96.0 & 99.1 & 86.1 & 75.8 & \\
\hline $\begin{array}{l}\text { Lifetime, but not } \\
\text { past } 12 \mathrm{mo}\end{array}$ & 1.4 & 0.5 & 4.9 & 1.9 & \\
\hline $\begin{array}{l}12 \text { mo, but not past } \\
30 \mathrm{~d}\end{array}$ & 1.5 & 0.3 & 5.6 & 7.6 & \\
\hline Past $30 \mathrm{~d}$ & 1.0 & 0.1 & 3.4 & 14.8 & \\
\hline Opioids (nonmedical) & & & & & $<.01$ \\
\hline Never used & 90.9 & 95.6 & 75.3 & 65.4 & \\
\hline $\begin{array}{l}\text { Lifetime, but not } \\
\text { past } 12 \mathrm{mo}\end{array}$ & 3.5 & 2.2 & 8.5 & 6.5 & \\
\hline $\begin{array}{l}12 \mathrm{mo} \text {, but not past } \\
30 \mathrm{~d}\end{array}$ & 3.7 & 1.6 & 10.6 & 14.5 & \\
\hline Past $30 \mathrm{~d}$ & 1.9 & 0.6 & 5.7 & 13.6 & \\
\hline Cocaine & & & & & $<.001$ \\
\hline Never used & 95.8 & 98.6 & 86.5 & 77.6 & \\
\hline $\begin{array}{l}\text { Lifetime, but not } \\
\text { past } 12 \text { mo }\end{array}$ & 1.8 & 1.0 & 4.6 & 6.0 & \\
\hline $\begin{array}{l}12 \text { mo, but not past } \\
30 \mathrm{~d}\end{array}$ & 1.4 & 0.2 & 5.6 & 5.8 & \\
\hline Past $30 \mathrm{~d}$ & 0.9 & 0.1 & 3.3 & 10.6 & \\
\hline Heroin & & & & & $<.0001^{\mathrm{b}}$ \\
\hline Never used & 99.4 & 99.8 & 98.7 & 89.8 & \\
\hline $\begin{array}{l}\text { Lifetime, but not } \\
\text { past } 12 \mathrm{mo}\end{array}$ & 0.3 & 0.1 & 0.7 & 2.7 & \\
\hline $\begin{array}{l}12 \mathrm{mo} \text {, but not past } \\
30 \mathrm{~d}\end{array}$ & 0.2 & 0.0 & 0.5 & 1.6 & \\
\hline Past $30 \mathrm{~d}$ & 0.2 & 0.1 & 0.1 & 5.9 & \\
\hline $\begin{array}{l}\text { Perceived risk of } \\
\text { using marijuana } \\
\text { occasionally }\end{array}$ & & & & & $<.01$ \\
\hline Not high & 82.6 & 78.7 & 96.3 & 91.0 & \\
\hline High & 17.4 & 21.3 & 3.7 & 9.0 & \\
\hline $\begin{array}{l}\text { Perceived risk of } \\
\text { trying SCs }\end{array}$ & & & & & .02 \\
\hline
\end{tabular}

studies in the United States have been focused on lifetime ${ }^{21}$ or pastyear use. ${ }^{16,22}$ Data on current use (commonly defined by national surveys as use within the past 30 days $^{25}$ ) are needed to determine which individuals are at highest risk for use and more immediate adverse outcomes (because discontinuation is common among individuals who had tried SCs in their lifetime or past year). ${ }^{16}$ Current use is also an important focus because newer and more dangerous SC compounds continue to emerge, ${ }^{2}$ and poisonings related to use have remained prevalent ${ }^{26,27}$ despite decreasing prevalence of use. Thus, our aim in this article is to determine risk factors for current use of SCs in a nationally representative sample of high school seniors with a particular focus on recency of use of other drugs. Because SC use is closely tied with marijuana use, we sought to differentiate risk of current SC users (who report marijuana use) from current marijuana users (a population at high risk for initiating SC use).

\section{METHODS}

\section{Procedure}

MTF is an annual, nationally representative survey of high school students in the United States. ${ }^{23} \mathrm{~A}$ different cross-section of students is surveyed each year, sampled from $\sim 130$ public and private schools throughout the 48 contiguous states. A multistage random sampling procedure is used in the geographic areas that are selected; then schools within areas are selected, followed by classes within schools. Approximately 15000 high school seniors are surveyed every year, and students are surveyed via 6 different survey forms, which are distributed randomly. Only survey forms 2 and 5, however, query current (30-day) use of SCs (neither of which query past-year or lifetime use). Therefore, current use is only assessed 


\begin{tabular}{lccccc}
\hline & $\begin{array}{c}\text { Full Sample } \\
(N=7517), \\
\text { Weighted } \%\end{array}$ & $\begin{array}{c}\text { Used Neither } \\
(n=5851, \\
78.1 \%), \\
\text { Weighted } \%\end{array}$ & $\begin{array}{c}\text { Marijuana } \\
\text { Only }(n=1502, \\
19.9 \%), \\
\text { Weighted } \%\end{array}$ & $\begin{array}{c}\text { Marijuana } \\
\text { and SCs } \\
(n=164,2.0 \%), \\
\text { Weighted \% }\end{array}$ & $\begin{array}{c}P \text { (Marijuana } \\
\text { Only Versus } \\
\text { Marijuana } \\
\text { and SCs) }\end{array}$ \\
\hline $\begin{array}{l}\text { Not high } \\
\text { High }\end{array}$ & 55.5 & 54.1 & 58.2 & 74.3 & \\
$\begin{array}{l}\text { Perceived risk of using } \\
\text { SCs occasionallyc }\end{array}$ & 44.5 & 45.9 & 41.8 & 25.7 & $<.01$ \\
$\quad$ Not high & 45.2 & 44.2 & 46.1 & 67.1 & \\
High & 54.8 & 55.8 & 53.9 & 32.9 & \\
\hline
\end{tabular}

Covariates in bivariable comparisons had missing data ranging from $0.0 \%$ to $5.1 \%$, with exception of race and/or ethnicity, which was missing $16.2 \%$ of cases because MTF does not provide this data for students identifying as races and/or ethnicities other than white, African American, or Hispanic. Percentages reflect case-complete data for each comparison. The 40 students who reported current SC use but no current marijuana use were excluded from these analyses. A Bonferroni correction was used for multiple testing for 5 drugs $(\alpha=.01)$ and for multiple testing of perceived risk associated with SC use $(\alpha=.025)$

a Alcohol use not significant when applying Bonferroni correction for multiple testing for 5 drugs ( $\alpha=01$ ).

${ }^{b}$ At least 1 cell contains small sample size (eg, $<5$ participants), but a specificity test was conducted by collapsing categories (eg, no lifetime use and lifetime, but not past 12-mo use) and $P$ values were identical.

c Perceived risk associated with SC use was only queried in half of the analytic sample.

TABLE 2 Multivariable Model Revealing Correlates of Self-Reported Current SC Use

\begin{tabular}{lcc}
\hline & aPR & $95 \% \mathrm{Cl}$ \\
\hline Age & & \\
$\quad<18$ & 1.00 & - \\
$\geq 18$ & 1.03 & $0.72-1.47$ \\
Sex & & \\
$\quad$ Male & 1.00 & - \\
$\quad$ Female & 0.93 & $0.65-1.35$ \\
Race and/or ethnicity & & \\
$\quad$ White & 1.00 & - \\
$\quad$ African American & 1.11 & $0.60-2.05$ \\
$\quad$ Hispanic & 1.23 & $0.77-1.97$ \\
Parent education & & \\
$\quad$ Low & 1.00 & - \\
$\quad$ Medium & 0.76 & $0.48-1.20$ \\
$\quad$ High & 0.63 & $0.40-1.00$ \\
Alcohol use in past 30 d & & \\
$\quad$ No & 1.00 & - \\
$\quad$ Yes & 2.09 & $1.20-3.64$ \\
IIIegal drugs other than marijuana & & \\
$\quad$ Used 0 & 1.00 & - \\
$\quad$ Used 1 & 2.18 & $1.44-3.29$ \\
Used 2-4 & 3.57 & $2.12-6.02$ \\
Perceived risk of using marijuana occasionally & & \\
$\quad$ Not high & 1.00 & - \\
High & 1.50 & $0.87-2.59$ \\
\hline
\end{tabular}

Current marijuana-only use was the comparison group to SC (plus marijuana) use. Missing data indicators were included to account for missing data. Results were nearly identical for model of case-complete data. aPR, adjusted prevalence ratio $\mathrm{Cl}$, confidence interval; —, not applicable.

in approximately a third of the sample.

MTF began asking about current SC use in 2014, and both available years of data (2014-2015) were aggregated for analysis. MTF protocols were approved by the University of Michigan Institutional Review Board, and these secondary analyses were exempt from review of the first authors' institutional review board.

\section{Measures}

Current SC use was assessed via the following question: "During the last 30 days, on how many occasions (if any) have you taken 'synthetic marijuana' ('K2,' 'Spice') to get high?" Answer options were: (1) none, (2) 1 to 2 days, (3) 3 to 5 days, (4) 6 to 9 days, (5) 10 to 19 days, and
(6) 20 to 30 days. A dichotomous variable was coded indicating whether 30-day use was reported, and another was coded to indicate whether SCs were reportedly used on $\geq 3$ days (vs $0-2$ days) to indicate higher-frequency use. Frequency of use was also recoded into a variable indicating use on 1 to 2 days, 3 to 9 days, and on $\geq 10$ days. Students were also asked about lifetime, past-year, and current (past 30-day) use of various other drugs. A variable was coded to indicate current marijuanaonly use versus marijuana use plus current SC use. To determine recency of use of other drugs, lifetime, pastyear, and 30-day use of alcohol, lysergic acid diethylamide (LSD), opioids (nonmedical use), cocaine, and heroin, were recoded to indicate (1) no lifetime use, (2) lifetime use but not past-year use, (3) past-year use but not past 30-day use, and (4) past 30-day use. Variables were also coded to indicate frequency of lifetime use of other drugs that were categorized into never used, used 1 to 2 times, and used $\geq 3$ times, and a count variable was also coded to indicate number of illegal drugs used (currently) other than marijuana. To assess perception of risk associated with marijuana use, students were asked, "How much do you think people risk harming themselves (physically or in other ways) if they smoke marijuana occasionally?" Answer options were: (1) no risk, (2) slight risk, (3) moderate risk, (4) great risk, and (5) can't say. On form 2 only, students were also asked the same question regarding (1) risk of trying SCs once or twice and (2) risk of using SCs occasionally. Dichotomous variables were coded to indicate "great risk" 24 (versus all other responses, with "can't say" coded as missing).

Regarding demographic characteristics, students were asked their age (predefined by MTF as <18 vs $\geq 18$ years), sex, and race and/ or ethnicity (predefined as African 
TABLE 3 Bivariable Tests Revealing Frequency of Lifetime Use of Other Drugs According to Current SC and Marijuana Use

\begin{tabular}{lccccc}
\hline & $\begin{array}{c}\text { Full Sample, } \\
\text { Weighted \% }\end{array}$ & $\begin{array}{c}\text { Used Neither, } \\
\text { Weighted \% }\end{array}$ & $\begin{array}{c}\text { Marijuana } \\
\text { Only, } \\
\text { Weighted \% }\end{array}$ & $\begin{array}{c}\text { Marijuana } \\
\text { and SCs, } \\
\text { Weighted \% }\end{array}$ & $\begin{array}{c}P \text { (Marijuana } \\
\text { Only Versus } \\
\text { Marijuana and } \\
\text { SCs) }\end{array}$ \\
\hline Alcohol & & & & & \\
Never used & 34.9 & 42.8 & 6.7 & 3.0 & .17 \\
Used 1-2 times & 9.4 & 10.8 & 4.2 & 3.2 & \\
Used $\geq 3$ times & 55.8 & 46.4 & 89.1 & 93.8 & \\
LSD & & & & & \\
Never used & 96.0 & 99.1 & 86.0 & 75.4 & $<.001$ \\
Used 1-2 times & 2.5 & 0.5 & 9.1 & 11.9 & \\
Used $\geq 3$ times & 1.5 & 0.4 & 4.9 & 12.7 & \\
Opioids & & & & & \\
(nonmedical) & & & & & \\
Never used & 90.9 & 95.6 & 75.2 & 64.8 & \\
Used 1-2 times & 4.0 & 2.4 & 9.4 & 10.8 & \\
Used $\geq 3$ times & 5.2 & 2.0 & 15.4 & 24.4 & \\
Cocaine & & & & & \\
Never used & 95.8 & 98.6 & 86.5 & 76.9 & \\
Used 1-2 times & 2.5 & 1.0 & 7.8 & 10.2 & \\
Used $\geq 3$ times & 1.7 & 0.4 & 5.7 & 13.0 & \\
Heroin & & & & & \\
Never used & 99.3 & 99.8 & 98.7 & 89.3 & $<.0001^{\mathrm{b}}$ \\
Used 1-2 times & 0.2 & 0.1 & 0.7 & 1.7 & \\
Used $\geq 3$ times & 0.4 & 0.1 & 0.6 & 9.0 & \\
\hline B & & & &
\end{tabular}

A Bonferroni correction was used for multiple testing for 5 drugs $(\alpha=.01)$.

${ }^{a}$ Nonmedical opioid use not significant when applying Bonferroni correction for multiple testing for 5 drugs $(\alpha=.01)$.

${ }^{b}$ At least 1 cell contains a small sample size (eg, $<5$ participants), but a specificity test was conducted by collapsing categories (ie, used $1-2$ times and used $\geq 3$ ) and $P$ value was identical

American, white, and Hispanic). To examine parent educational attainment (a common indicator of socioeconomic status), the mean score for both parents (or a raw score if only 1 parent) was coded into tertiles representing low $(1.0-3.0)$, medium (3.5-4.0), and high (4.5-6.0) education. ${ }^{28-30}$ Coding of sociodemographic variables was based on previous MTF analyses, and all have been shown to be correlates of drug use. ${ }^{16,30-32}$

\section{Statistical Analyses}

Prevalence of self-reported use was estimated by using all cases with SC data $(N=7805)$. Each covariate was then examined in a bivariable manner, comparing demographic and other drug use characteristics between marijuana-only users and SC (plus marijuana) users by using Rao-Scott $\chi^{2}$ tests. ${ }^{33}$ Characteristics for the full sample and for those not reporting current use of marijuana or SCs were also computed for descriptive purposes. All demographic and drug use covariates were then fit into a multivariable generalized linear model by using Poisson and log link with current SC use (plus marijuana use) compared with current marijuana-only use as the outcome. Missing data were addressed in the model as in previous MTF analyses by entering an additional category for each covariate to prevent casewise deletion and ensuring that results match those from a model in which the case-complete data set was utilized. ${ }^{16,32,34,35}$ Bivariable tests were then repeated for each covariate, but comparing frequency of use of each other drug. Finally, bivariable tests were conducted to determine if there were differences between covariates according to frequency of current SC use. Bonferroni corrections were used when appropriate for multiple comparisons. All analyses were design-based for survey data ${ }^{36}$ by using survey sample weights provided from MTF. Stata 13.1 software (StataCorp, College Station, TX) was used for all analyses.

\section{RESULTS}

Current (30-day) SC use was reported by $2.9 \%$ of students, and there was not a significant difference in prevalence by year $(P=.73)$. Eight out of $10(80.6 \%)$ SC users also reported current marijuana use, 91.1\% reported past-year use, and 95.7\% reported lifetime marijuana use. The $40 \mathrm{SC}$ users who reported no current marijuana use were omitted from bivariable and multivariable analyses.

Figure 1 presents the proportions of marijuana and SC users in the analytic sample. Approximately 1 in 10 students $(9.3 \%)$ reporting current marijuana use also reported current SC use. Table 1 presents sample demographics and self-reported drug use, as well as comparisons between current marijuana and SC (plus marijuana) use. Compared with current marijuana-only users, students reporting SC use were more likely to have parents with lower educational attainment $(P=.02)$. Compared with marijuana-only users, SC users were more likely to report use and more recent and/or current use of each drug with exception of alcohol $(P s<.01)$. Specifically, compared with marijuana-only users, prevalence of current use of other drugs was substantially higher among SC users for LSD (14.8\% vs $3.4 \%$ ), opioids ( $13.6 \%$ vs $5.7 \%$ ), cocaine $(10.6 \%$ vs $3.3 \%)$, and heroin ( $5.9 \%$ vs $0.1 \%$ ). SC users were also more likely than marijuana-only users to report high perception of risk of using marijuana occasionally $(P<.01)$ and less likely to report high perception of risk of trying SCs and using SCs occasionally $(P s<.025)$. Results were similar when examining these associations in a multivariable 
TABLE 4 Characteristics of SC Users According to Frequency of Self-Reported Current Use

\begin{tabular}{|c|c|c|c|c|}
\hline & $\begin{array}{c}\text { Used } 1-2 \mathrm{~d} \\
(n=122,50.3 \%) \\
\text { Weighted } \%\end{array}$ & $\begin{array}{c}\text { Used 3-9 d } \\
(n=55,20.4 \%) \\
\text { Weighted \% }\end{array}$ & $\begin{array}{c}\text { Used } \geq 10 \mathrm{~d} \\
(n=57,29.3 \%) \\
\text { Weighted } \%\end{array}$ & $P$ \\
\hline Age & & & & .72 \\
\hline$<18$ & 39.4 & 33.2 & 33.2 & \\
\hline$\geq 18$ & 60.6 & 66.8 & 66.8 & \\
\hline Sex & & & & $<.01$ \\
\hline Male & 47.2 & 64.5 & 77.9 & \\
\hline Female & 52.8 & 35.5 & 22.1 & \\
\hline Race and/or ethnicity & & & & $<.001$ \\
\hline White & 56.7 & 55.1 & 36.0 & \\
\hline African American & 6.4 & 23.5 & 43.4 & \\
\hline Hispanic & 36.9 & 21.3 & 20.6 & \\
\hline Parent education & & & & .36 \\
\hline Low & 44.3 & 36.3 & 52.1 & \\
\hline Medium & 25.8 & 38.1 & 17.2 & \\
\hline High & 29.9 & 25.6 & 30.7 & \\
\hline \multicolumn{5}{|l|}{ Current (30-d) use of other drugs } \\
\hline Alcohol & & & & .87 \\
\hline No & 27.6 & 23.0 & 28.3 & \\
\hline Yes & 72.4 & 77.0 & 71.7 & \\
\hline Marijuana & & & & $<.01$ \\
\hline Used 0 times & 19.1 & 14.7 & 24.2 & \\
\hline Used $1-19$ times & 58.9 & 61.2 & 26.9 & \\
\hline Used $\geq 20$ times & 22.0 & 24.1 & 48.9 & \\
\hline $\begin{array}{l}\text { Illegal drugs other than } \\
\text { marijuana }\end{array}$ & & & & $<.001$ \\
\hline Used 0 & 85.8 & 59.0 & 79.7 & \\
\hline Used 1 & 12.0 & 29.0 & 6.2 & \\
\hline Used 2-4 & 2.2 & 12.1 & 14.2 & \\
\hline $\begin{array}{l}\text { Perceived risk of using } \\
\text { marijuana occasionally }\end{array}$ & & & & .35 \\
\hline Not high & 93.5 & 87.3 & 86.4 & \\
\hline High & 6.5 & 12.7 & 13.6 & \\
\hline Perceived risk of trying SCs & & & & .36 \\
\hline Not high & 81.0 & 62.4 & 72.7 & \\
\hline High & 19.0 & 37.6 & 27.3 & \\
\hline $\begin{array}{l}\text { Perceived risk of using SCs } \\
\text { occasionally }\end{array}$ & & & & .08 \\
\hline Not high & 72.4 & 39.6 & 50.3 & \\
\hline High & 27.6 & 60.4 & 49.7 & \\
\hline
\end{tabular}

Current use of the 4 illegal drugs other than marijuana (LSD, cocaine, opioids, and heroin) were collapsed into a count variable to account for too few participants in some cells.

manner (Table 2). Specifically, compared with marijuana-only users, SC users had significantly lower prevalence of having parents with higher education $(P<.05)$, significantly higher prevalence of reporting current alcohol use $(P<$ $.01)$, and increased prevalence of current use of number of other illegal drugs $(P s<.001)$.

As shown in Table 3, compared with marijuana-only users, SC users were more likely to report use and more frequent lifetime use (used $\geq 3$ times) of LSD (12.7\% vs $4.9 \%)$, cocaine
(13.0\% vs $5.7 \%)$, and heroin $(9.0 \%$ vs $0.6 \%)$.

Finally, among those reporting current SC use (Table 4), those reporting use on $\geq 10$ days were more likely to identify as boys $(P<$ $.01)$ or African American $(P<.001)$. Likewise, those reporting SC use on $\geq 10$ days were also more likely to report current use of marijuana $\geq 20$ times in the past month, with approximately half (48.9\%) reporting such high-frequency marijuana use $(P<.01)$. Although 8 out of 10 students reporting $\mathrm{SC}$ use on $\geq 10$ days reported not using any of the 4 other illegal drugs in the past 30 days, the proportion reporting use of 2 to 4 other drugs grew as frequency of SC use increased $(P<.001)$.

\section{DISCUSSION}

This is the first nationally representative study in which current (past 30-day) use of SCs was examined. Other large-scale studies have been focused on pastyear and lifetime use, but research was needed on those at highest risk for immediate adverse outcomescurrent users. Three percent of high school seniors in the United States reported current use of these compounds, and $1.4 \%$ of high school seniors reported using on $\geq 3$ days in the past month (constituting half of current users). This finding is important because it implies that half of current users report using SCs more than once or twice, which may suggest more than just mere “experimentation.” In fact, a fifth of current users reported use on 20 to 30 days in the past 30 days, suggesting daily or almost-daily use. Boys, African American students, and users of various other drugs were identified to be at particular risk for frequent SC use. A previous study of past-year SC use in MTF found that African American students were actually at lower risk for use (until controlling for other covariates). ${ }^{16}$ These findings suggest that risk profiles appear to be different for students who are trying SCs and for those who are using currently and/or frequently.

In this study, we corroborated previous studies in that SC use is closely tied to marijuana use, ${ }^{16-20}$ with 8 out of 10 current SC users also reporting current marijuana use. We also found that approximately half of frequent SC users reported using marijuana $\geq 20$ times during the past month, further highlighting links between these drugs and suggests 
those who may be dependent on marijuana may be more likely to engage in frequent SC use. Because so few current SC users deny lifetime marijuana use, and because a recent study revealed that marijuana use predicts SC use but not vice versa, ${ }^{20}$ it is important to determine which marijuana users are at risk for using these new potentially dangerous compounds. Results pertaining to other drug use suggest that current SC use appears to be part of a more extensive polydrug use repertoire involving other illegal drugs that are less prevalent among marijuanaonly users. Temporal order of drug initiation could not be determined, but these associations suggest the need to target marijuana users who also use other drugs to help prevent initiation of SCs.

Although fewer SC users perceived that SC experimentation and occasional use are at great risk of harming themselves physically or in other ways (compared with marijuana-only users), SC users were more likely than marijuana-only users to report high perception of risk of using marijuana occasionally. This finding may indicate a lack of knowledge about the relative health risks of SC compared with marijuana. Although marijuana itself is not risk-free, the current state of the literature on SC-related harms clearly indicates that SC products are becoming more dangerous, because new generations of SC that are more potent and bind more heavily to cannabinoid receptors are replacing first and second generations. ${ }^{2}$ If there are students using SCs because they genuinely believe they are less risky than marijuana, this misconception should be addressed through better education programs stressing the greater danger posed by SCs. It is possible, however, that the high perception of risk associated with marijuana use was regarding risk of arrest rather than direct health risks because marijuana is a Schedule I drug in the United States. More research is needed to determine the extent to which marijuana users are likely to resort to SC use to evade arrest, or positive drug test results, or the stigma associated with use of illegal drugs.

Limitations are noted. Current use was not queried among eighthgraders or 10th-graders, and it was not queried on the same randomized survey forms that ask about past-year use. SC use was only queried on 2 of 6 survey forms. To help ensure generalizability of findings, we confirmed that there were no significant differences by any covariate between the survey forms used in these analyses and the other 4 forms that did not ask about current SC use. Although other drugs queried have been validated in recent decades by $\mathrm{MTF}^{24}$ a limitation is that current SC use is a new variable that does not appear to have been tested in other MTF analyses. Many adolescents also might not have been capable of accurately reporting educational attainment of their parent(s) or guardian(s). Missing data were an issue, in part, because MTF surveys are administered via paper and pencil, and MTF does not provide race and/or ethnicity data for students identifying as any race and/or ethnicity other than white, African American, or Hispanic. This was addressed in our multivariable model similar to how this has been addressed in many previous analyses. ${ }^{16,32,34,35}$ Adolescents who dropped out of school were not surveyed, and given that this study was cross-sectional, temporal associations could not be examined. Because higher frequency (use $\geq 6$ times) current SC use and lifetime use of other drugs was rare, models could not be used to examine associations in a multivariable manner with precision. The usual limitations applicable to survey studies also apply: that use is self-reported and therefore relies on memory and may be affected by social desirability or dishonest reporting. There was no analytic confirmation of self-report drug use.

Although prevalence of past-year SC use has been decreasing in recent years, ${ }^{22,23}$ we estimate that $3 \%$ of high school seniors have used in the past month. These are students who are at current risk of experiencing adverse health outcomes from the newest generation of SCs and also because of concurrent use of other drugs. Although previous studies have revealed that marijuana users are at high risk for use, this study revealed risk factors among current marijuana users that increase risk of current use and higher-frequency use of SCs. Prevention needs to be focused primarily on marijuana users, especially marijuana users with risk factors discovered in this analysis. Marijuana users who use other drugs in particular are at highest risk for currently using SCs, so particular focus needs to be paid to these individuals at high risk.

\section{ABBREVIATIONS}

MTF: Monitoring the Future SC: synthetic cannabinoid

FINANCIAL DISCLOSURE: The authors have indicated they have no financial relationships relevant to this article to disclose.

FUNDING: Research reported in this publication was supported by the National Institute on Drug Abuse of the National Institutes of Health under award K01DA038800 (principal investigator: Palamar). The content is solely the responsibility of the authors and does not necessarily represent the official views of the National Institutes of Health. The Inter-university Consortium for Political and Social Research and Monitoring the Future principal investigators also had no role in analysis, interpretation of results, or in the decision to submit this manuscript. This project was also supported by R01DA037866 (Martins), and Barratt is 
supported by a fellowship from the National Health and Medical Research Council (APP1070140). The National Drug and Alcohol Research Centre and the National Drug Research Institute are supported by funding from the Australian government under the Substance Misuse Prevention and Service Improvement Grants Fund. Funded by the National Institutes of Health (NIH).

POTENTIAL CONFLICT OF INTEREST: The authors have indicated they have no potential conflicts of interest to disclose.

\section{REFERENCES}

1. Auwärter V, Dargan PI, Wood DM. Synthetic cannabinoid receptor agonists. In: Dargan PI, Wood DM, eds. Novel Psychoactive Substances. Classification, Pharmacology and Toxicology. Amsterdam, Netherlands: Academic Press; 2013:317-343

2. Zawilska JB, Andrzejczak D. Next generation of novel psychoactive substances on the horizon - a complex problem to face. Drug Alcohol Depend. 2015;157:1-17

3. European Monitoring Centre for Drugs and Drug Addiction; Europol. EU Drug Markets Report. Lisbon, Portugal: EMCDDA; 2016

4. Dalton VS, Wang H, Zavitsanou K. HU210-induced downregulation in cannabinoid CB1 receptor binding strongly correlates with body weight loss in the adult rat. Neurochem Res. 2009;34(7):1343-1353

5. van Amsterdam J, Brunt T, van den Brink W. The adverse health effects of synthetic cannabinoids with emphasis on psychosis-like effects. J Psychopharmacol. 2015;29(3):254-263

6. Wiley JL, Marusich JA, Huffman JW. Moving around the molecule: relationship between chemical structure and in vivo activity of synthetic cannabinoids. Life Sci. 2014;97(1):55-63

7. Seely KA, Lapoint J, Moran JH, Fattore L. Spice drugs are more than harmless herbal blends: a review of the pharmacology and toxicology of synthetic cannabinoids. Prog Neuropsychopharmacol Biol Psychiatry. 2012;39(2):234-243

8. Tait RJ, Caldicott D, Mountain D, Hill SL, Lenton S. A systematic review of adverse events arising from the use of synthetic cannabinoids and their associated treatment. Clin Toxicol (Phila). 2016;54(1):1-13

9. McQuade D, Hudson S, Dargan PI, Wood DM. First European case of convulsions related to analytically confirmed use of the synthetic cannabinoid receptor agonist AM-2201. Eur J Clin Pharmacol. 2013;69(3):373-376

10. Hermanns-Clausen M, Kneisel S, Szabo B, Auwärter V. Acute toxicity due to the confirmed consumption of synthetic cannabinoids: clinical and laboratory findings. Addiction. 2013;108(3):534-544

11. Buser GL, Gerona RR, Horowitz BZ, et al. Acute kidney injury associated with smoking synthetic cannabinoid. Clin Toxicol (Phila). 2014;52(7):664-673

12. Takematsu M, Hoffman RS, Nelson LS, Schechter JM, Moran JH, Wiener SW. A case of acute cerebral ischemia following inhalation of a synthetic cannabinoid. Clin Toxicol (Phila) 2014;52(9):973-975

13. Mcllroy G, Ford L, Khan JM. Acute myocardial infarction, associated with the use of a synthetic adamantylcannabinoid: a case report. BMC Pharmacol Toxicol. 2016;17:2

14. Winstock A, Lynskey M, Borschmann R, Waldron J. Risk of emergency medical treatment following consumption of cannabis or synthetic cannabinoids in a large global sample. $J$ Psychopharmacol. 2015;29(6):698-703

15. Zaurova M, Hoffman RS, Vlahov D, Manini AF. Clinical effects of synthetic cannabinoid receptor agonists compared with marijuana in emergency department patients with acute drug overdose. J Med Toxicol. 2016;12(4):335-340

16. Palamar JJ, Acosta P. Synthetic cannabinoid use in a nationally representative sample of US high school seniors. Drug Alcohol Depend. 2015;149:194-202

17. Winstock AR, Barratt MJ. Synthetic cannabis: a comparison of patterns of use and effect profile with natural cannabis in a large global sample. Drug Alcohol Depend. 2013;131(1-2):106-111
18. Barratt MJ, Cakic V, Lenton S. Patterns of synthetic cannabinoid use in Australia. Drug Alcohol Rev. 2013;32(2):141-146

19. Vandrey R, Dunn KE, Fry JA, Girling ER. A survey study to characterize use of Spice products (synthetic cannabinoids). Drug Alcohol Depend. 2012;120(1-3):238-241

20. Ninnemann AL, Jeong Choi $H$, Stuart GL, Temple JR. Longitudinal predictors of synthetic cannabinoid use in adolescents. Pediatrics. 2017;139(4):e20163009

21. Clayton HB, Lowry R, Ashley C, Wolkin A, Grant AM. Health risk behaviors with synthetic cannabinoids versus marijuana. Pediatrics. 2017;139(4):e20162675

22. Keyes KM, Rutherford C, Hamilton A, Palamar JJ. Age, period, and cohort effects in synthetic cannabinoid use among US adolescents, 2011-2015. Drug Alcohol Depend. 2016;166:159-167

23. Johnston LD, O'Malley PM, Miech RA, Bachman JG, Schulenberg JE. Monitoring the Future National Survey Results on Drug Use, 1975-2016. Overview, Key Findings on Adolescent Drug Use. Ann Arbor, MI: Institute for Social Research, The University of Michigan; 2017

24. Miech RA, Johnston LD, O'Malley PM, Bachman JG, Schulenberg JE. Monitoring the Future National Survey Results on Drug Use, 1975-2014, Vol. I: Secondary School Students. Ann Arbor, MI: Institute for Social Research, University of Michigan; 2015

25. Center for Behavioral Health Statistics and Quality. 2015 National Survey on Drug Use and Health Public Use File Codebook. Rockville, MD: Substance Abuse and Mental Health Services Administration; 2016

26. Law R, Schier J, Martin C, Chang A, Wolkin A; Centers for Disease Control (CDC). Notes from the field: increase 
in reported adverse health effects related to synthetic cannabinoid use - United States, January-May 2015. MMWR Morb Mortal Wkly Rep 2015;64(22):618-619

27. Riederer AM, Campleman SL, Carlson $\mathrm{RG}$, et al; Toxicology Investigators Consortium (ToxIC). Acute poisonings from synthetic cannabinoids - 50 U.S. toxicology investigators consortium registry sites, 2010-2015. MMWR Morb Mortal Wkly Rep. 2016;65(27):692-695

28. Bachman JG, Staff J, 0’Malley PM, Freedman-Doan P. Relationships Between Paid Work Intensity and Problem Behaviors Vary by RaceEthnicity and Socioeconomic Status: Evidence From the Monitoring the Future Study. Ann Arbor, MI: Institute for Social Research, University of Michigan; 2013:75

29. Johnston LD, O'Malley PM, Miech RA, Bachman JG, Schulenberg JE.
Demographic Subgroup Trends Among Adolescents in the Use of Various Licit and IIlicit Drugs, 19752016. Ann Arbor, MI: Institute for Social Research, University of Michigan; 2017:88

30. Wallace JM Jr, Vaughn MG, Bachman JG, O'Malley PM, Johnston LD, Schulenberg JE. Race/ethnicity, socioeconomic factors, and smoking among early adolescent girls in the United States. Drug Alcohol Depend. 2009;104(suppl 1):S42-S49

31. Palamar JJ, Zhou S, Sherman S, Weitzman M. Hookah use among U.S. high school seniors. Pediatrics. 2014;134(2):227-234

32. Palamar JJ, Shearston JA, Dawson EW, Mateu-Gelabert P, Ompad DC. Nonmedical opioid use and heroin use in a nationally representative sample of us high school seniors. Drug Alcohol Depend. 2016;158:132-138
33. Rao JNK, Scott AJ. On chi-squared tests for multiway contingency tables with cell proportions estimated from survey data. Ann Stat. 1984;12(1):46-60

34. Terry-McEIrath YM, O'Malley PM, Johnston LD, Bray BC, Patrick ME, Schulenberg JE. Longitudinal patterns of marijuana use across ages 18-50 in a US national sample: a descriptive examination of predictors and health correlates of repeated measures latent class membership. Drug Alcohol Depend. 2017;171:70-83

35. Terry-McEIrath YM, Chriqui JF, 0'Malley PM, Chaloupka FJ, Johnston LD. Regular soda policies, school availability, and high school student consumption. Am J Prev Med. 2015;48(4):436-444

36. Heeringa SG, West BT, Berglund PA. Applied Survey Data Analysis. London, United Kingdom: Chapman and Hall; 2010 